\title{
In Vitro Suppression of Programmed Cell Death of B Cells by Tissue Inhibitor of Metalloproteinases-1
}

\author{
Liliana Guedez, ${ }^{\star}$ William G. Stetler-Stevenson,, Linda Wolff, ${ }^{\S}$ Jiun Wang, ${ }^{\star}$ Paula Fukushima, ${ }^{\star}$ Adnan Mansoor, ${ }^{\star}$ \\ and Maryalice Stetler-Stevenson* \\ *Flow Cytometry Unit, Hematopathology Section and ${ }^{\ddagger}$ Extracellular Matrix Pathology Section, Laboratory of Pathology, Division of \\ Clinical Sciences, and ${ }^{\S}$ Laboratory of Cellular Oncology, Division of Basic Sciences, National Cancer Institute, Bethesda, \\ Maryland 20892-1500
}

\begin{abstract}
Cellular pathways for induction of programmed cell death (PCD) have been identified, but little is known about specific extracellular matrix processes that may affect apoptosis along those pathways. In this study, a series of Burkitt's lymphoma (BL) cell lines were assayed for their expression of tissue inhibitor of metalloproteinases (TIMP)-1. Results indicate that TIMP-1-positive BL lines show resistance to cold-shock-induced apoptosis. Furthermore, recombinant TIMP-1, but not TIMP-2 or a synthetic metalloproteinase inhibitor (BB-94), confers resistance to apoptosis induced by both CD95-dependent and -independent (cold shock, serum deprivation, and $\gamma$-radiation) pathways in TIMP-1-negative BL lines. TIMP-1 suppression of PCD is not due to metalloproteinase inhibition, as reduction and alkylation of the TIMP-1 did not abolish this activity. Retroviral induction of TIMP-1 not only resulted in cell survival but also in continued DNA synthesis for up to $5 \mathrm{~d}$ in the absence of serum, while controls underwent apoptosis. This resistance to apoptosis is reversed by anti-TIMP-1 antibodies, demonstrating that secreted TIMP-1 is active in blocking apoptosis. Furthermore, TIMP-1 upregulation induced expression of Bcl$\mathrm{X}_{\mathrm{L}}$ but not Bcl-2 as well as decreased NF- $\mathrm{KB}$ activity as compared with controls. These results demonstrate that TIMP-1 suppresses apoptosis in B cells and suggests a novel activity for TIMP-1 in tissue homeostasis. (J. Clin. Invest. 1998. 102:2002-2010.) Key words: Bcl-X • Bcl-2 • extracellular matrix $\bullet$ Burkitt's lymphoma $\bullet$ metalloproteinases
\end{abstract}

\section{Introduction}

Programmed cell death (PCD), ${ }^{1}$ or apoptosis, is now recognized as playing a central role in development and tissuespecific functions in such diverse processes as regulation of immune responses, angiogenesis, and organogenesis (1-3).

Address correspondence to M. Stetler-Stevenson, Flow Cytometry Unit, Hematopathology Section, Laboratory of Pathology, DCS, NCI, Bldg. 10, Room 2A33, MSC \#1500, 10 Center Drive, Bethesda, MD 20892-1500. Phone: 301-402-1424; FAX: 301-402-0043; E-mail: stetler@box-s.nih.gov

Received for publication 22 January 1998 and accepted in revised form 11 October 1998.

1. Abbreviations used in this paper: BRDU, bromodeoxyuridine; ECM, extracellular matrix; MMP, matrix metalloproteinase; PCD, programmed cell death; PI, propidium iodide; TIMP, tissue inhibitor of metalloproteinases.

The Journal of Clinical Investigation

Volume 102, Number 11, December 1998, 2002-2010

http://www.jci.org
In these processes, components of the extracellular matrix (ECM) (4) and in particular basement membrane act as survival factors and suppress apoptosis. Proteolytic modification of matrix organization or disruption of cell-matrix contacts can result in initiation of PCD in epithelial cells, with induction of specific molecular effectors of apoptosis such as caspases $(3,4)$. Recently, it was shown that proteolytic processing of TNF- $\alpha$ and FAS ligand (FasL) from the surface of lymphoid cells by matrix metalloproteinase-like activity can also alter PCD $(5,6)$. We have recently examined the expression of matrix metalloproteinases (MMPs) and their endogenous inhibitors, the tissue inhibitors of metalloproteinases (TIMPs), in human normal and neoplastic lymphoid cell lines (7). In this study, TIMP-1 secretion was shown only by normal activated tonsillar B cells and by a subset of high-grade Burkitt's lymphomas but not by quiescent peripheral blood cells or follicular lymphoma cell lines. MMP expression was variable and did not correlate with TIMP-1 production. These results are in agreement with previous reports from our laboratory and others that TIMP-1 expression correlates with clinical grade in non-Hodgkin's lymphomas as well as in other malignancies but did not correlate with MMP expression (8-10). Therefore, these effects of TIMPs may be independent of their ability to inhibit MMPs $(11,12)$. In addition, TIMP-1 promotes survival of serum-dependent cell lines, including Burkitt's lymphomas, in serum-free conditions (13). Together, these findings suggest that extracellular matrix proteases or their inhibitors (TIMPs) may directly influence malignancy and PCD in B cells as well as in other cell types. The present study was therefore undertaken to determine whether TIMP-1 regulates apoptosis in $\mathrm{B}$ cells. The results of our study demonstrate that TIMP-1 directly controls apoptosis through a novel, non-MMP inhibitory pathway and suggest that this protein plays a pivotal role in maintenance of $\mathrm{B}$ cell homeostasis.

\section{Methods}

Cells. Burkitt's lymphoma cell lines used in this study (see Table I) were kindly provided by Dr. Ian Magrath, Chief of Lymphoma Biology Section, National Cancer Institute (NCI) (14-17) or purchased from ATCC (Rockville, MD). Hyperplastic tonsils were obtained fresh in saline. A cell suspension was prepared. The tonsillar cells were cultured in serum-free conditions overnight in the absence or presence of $400 \mathrm{ng} / \mathrm{ml}$ of rTIMP-1. Cell lines were cultured in RPMI 1640 obtained from GIBCO BRL (Rockville, MD), supplemented with $10 \% \mathrm{FBS}$ (without serum as indicated), and antibiotics, $5 \% \mathrm{CO}_{2}$, at $37^{\circ} \mathrm{C}$.

TIMP-1 specificity. JD38 cells were preincubated with both native recombinant TIMP-1 and reduced and alkylated TIMP-1 (50-250 $\mathrm{ng} / \mathrm{ml})$, recombinant TIMP-2 $(250-500 \mathrm{ng} / \mathrm{ml})$, and the synthetic MMP inhibitor BB-94 $(5 \mu \mathrm{M})$ obtained from British Biotech (Oxford, England) for $24 \mathrm{~h}$ before induction of apoptosis.

TIMP-1 dose response. JD38 cells $\left(2.5 \times 10^{5}\right)$ were cultured in a 96-well plate with serum-free media and in the presence or absence of 
rTIMP-1 (1.43-143 nM) prepared as previously described (18). After $48 \mathrm{~h}$, the number of viable cells was determined.

Apoptosis-inducing treatments. In all methods, cells were monitored for apoptosis over extended periods of time (4-72 h), and optimal time points for detection of apoptosis were determined. Coldshock induction of apoptosis was as described previously (19). In brief, $1 \times 10^{6}$ cells $/ \mathrm{ml}$ were incubated at $4^{\circ} \mathrm{C}$ for $4 \mathrm{~h}$ and returned to $37^{\circ} \mathrm{C}$ for an additional $4-8 \mathrm{~h}$. Anti-Fas apoptosis was induced as follows: $2 \times 10^{5}$ cells $/ \mathrm{ml}$ were treated for $6-24 \mathrm{~h}$ with $200 \mathrm{ng} / \mathrm{ml}$ antiCD95 monoclonal antibody clone $\mathrm{CH}-11$ purchased from Immunotech (Miami, FL) at $37^{\circ} \mathrm{C}$. For serum deprivation, cells were incubated for $48 \mathrm{~h}$ in serum-free RPMI at $37^{\circ} \mathrm{C}$. Cells were also treated with 800 rads using a Gamma Cell 40 irradiator, followed by incubation in fresh RPMI at $37^{\circ} \mathrm{C}$. Apoptosis was also induced in TIMP-1 positive cells grown in serum-free media and with anti-TIMP-1 monoclonal antibody $(5 \mu \mathrm{g} / \mathrm{ml})$. Anti-TIMP-2 and irrelevant isotype were used as controls. The TIMP-1 and TIMP-2 antibodies were purchased from Oncogene Research Products (Cambridge, MA).

Detection of apoptosis. Apoptosis was measured by at least three methods for each condition. All cells were reviewed microscopically for morphological evidence of apoptosis such as blebbing and nuclear condensation. Apoptosis was detected using flow cytometry by the following methods: light scatter as previously described (20) and decreased DNA content by using propidium iodide (PI) staining (subdiploid peak characteristic of DNA fragmentation), Annexin V staining, assay of Caspase-3 activity, and TUNEL method (detects TdT incorporation of labeled nucleotides into DNA strand breaks). DNA content analysis by PI staining and the TUNEL method were combined using the Fluorescein Cell Death Detection Kit in a modification of the manufacturer's protocol (Boehringer Mannheim, Indianapolis, IN). In brief, $2 \times 10^{6}$ cells were washed twice in PBS with $1 \%$ BSA and fixed in $2 \%$ paraformaldehyde for $30 \mathrm{~min}$ at room temperature. Cells were then washed twice with PBS, permeabilized with $0.1 \%$ Triton-X 100 and $2 \times$ SSC for $2 \mathrm{~min}$ on ice and resuspended in $50 \mu \mathrm{L}$ of TUNEL reaction media from the Boehringer's kit. After $1 \mathrm{~h}$ incubation at $37^{\circ} \mathrm{C}$, cells were washed with PBS and resuspended in 1 $\mathrm{ml}(5 \mathrm{mg} / \mathrm{ml})$ PI from Calbiochem (La Jolla, CA) and $1 \mu \mathrm{lof} 5 \mathrm{mg} / \mathrm{ml}$ Ribonuclease A from Worthington Biochemical (Freehold, NJ). Apoptosis was detected in tonsillar cells by using Annexin V-FITC from Caltag (Burlingame, CA) in conjunction with PE-anti-CD3 antibody ( $T$ cells), anti-CD10 antibody (germinal center B cells) obtained from Dako (Carpinteria, CA), and PerCP-anti-CD20 antibody from Becton Dickinson (San Jose, CA). Activation of caspase-3 was detected by using fluorogenic substrate PhiPhilux obtained from OncoImmunin (College Park, MD) according to the manufacturer's protocol. Flow cytometric analysis was done on a FACScan ${ }^{\circledR}$ from Becton Dickinson (San Jose, CA).

TIMP-1 retroviral construct. The TIMP-1-negative Burkitt's lymphoma cell line JD-38 was selected, and LXSN retroviral transduction was used to induce TIMP-1 expression. JD-38 cells (see Table I) were obtained from Dr. Ian Magrath (Lymphoma Biology Section, NCI). TIMP-1 cDNA was obtained by PCR and subcloned into LXSN by using DNA recombinant techniques. Empty LXSN or TIMP-1LXSN constructs were transfected into packaging lines. Nonadherent JD38 cells were then cocultured with adherent LXSN-TIMP-1 packaging cells (GP+envAM12) for $48 \mathrm{~h}$ (21). LXSN TIMP-1-infected JD38 cells were then selected using 2,500 $\mu \mathrm{g} / \mathrm{ml} \mathrm{G} 418$ for $10 \mathrm{~d}$. Individual clones were isolated by repeated limiting dilution. Clonality was confirmed by restriction enzyme digestion with Sma I and Southern blot analysis, with unique sites of integration detected in the JD38 cell clones used in this study.

Northern blot analysis. Total RNA $(7.5 \mu \mathrm{g})$, extracted from cell suspensions by using RNAzol purchased from Cinna/Biotecx Laboratories (Houston, TX) was electrophoresed on $1 \% \mathrm{wt} / \mathrm{vol}$ agaroseformaldehyde gel before transfer onto nylon filters GeneScreen Plus from Dupont, NEN products (Boston, MA) and ultraviolet (UV) cross-linking to the filter. Blots were hybridized using standard conditions with TIMP-1 and GAPDH probes labeled with a $\left[{ }^{32} \mathrm{P}\right] \mathrm{dCTP}$ by using a random primer labeling kit from Bethesda Research Laboratories (Gaithersburg, MD).

Western blot analysis. Conditioned media was collected from Burkitt's lymphoma cell lines after $48 \mathrm{~h}$ incubation of $3 \times 10^{5} \mathrm{cells} / \mathrm{ml}$ at $37^{\circ} \mathrm{C}$ and $5 \% \mathrm{CO}_{2}$ in AIMV or serum-free RPMI media both purchased from GIBCO BRL (Gaithersburg, MD). Supernatants were cleared of cells by centrifugation and protein concentration determined by BCA protein assay from Pierce (Rockford, IL). Equal amounts of proteins in $20-40 \mu \mathrm{L}$ of conditioned media were electrophoresed in a $4-20 \%(\mathrm{wt} / \mathrm{vol})$, polyacrylamide/SDS gel at $100 \mathrm{~V}$ for $60 \mathrm{~min}$ at room temperature and electroblotted onto polyvinylidine difluoride membranes from Novex (San Diego, CA) and at $10 \mathrm{~V}$ for $25 \mathrm{~min}$ at room temperature by using a semidry BIO-RAD electroblotter (Indianapolis, IN). Rabbit polyclonal antibodies against TIMP-1 kindly provided by Dr. Bente Birkedahl-Hansen (Extracellular Matrix Pathology Section, Laboratory of Pathology, NCI) and murine monoclonal TIMP-1 antibody purchased from Oncogene Sciences (La Jolla, CA); dilutions of 1:1,000 were used. Also, cytoplasmatic proteins were extracted using RIPA buffer $(150 \mathrm{mM} \mathrm{NaCl}, 1 \%$ NP-40, 0.1\% SDS, $50 \mathrm{mM}$ Tris-HCL, pH 8.0) containing protease inhibitors from JD38 cells, LXSN-JD38 cells and TIMP-1-JD38 cells, and $50 \mu \mathrm{g}$ of proteins fractionated by electrophoresis as explained previously. Antibodies against Bcl-2, Bcl- $\mathrm{X}_{\mathrm{L} / \mathrm{S}}, \mathrm{p}-65 \mathrm{NF} \kappa \mathrm{B}$, and IкB $\alpha$ were purchased from Santa Cruz Biotechnology (San Diego, CA) and used. These blots were developed with a horseradish peroxidaseconjugated goat anti-rabbit immunoglobulin or goat anti-mouse both from Pierce and a chemiluminesence kit from DuPont, NEN.

Cell cycle and DNA synthesis. TIMP-1-JD38 cell clones and LXSNJD38 cells $\left(5 \times 10^{5} / \mathrm{ml}\right)$ were cultured in the presence or absence of serum for $1-5$ d. $10 \mu \mathrm{M}$ bromodeoxyuridine (BRDU) from Calbiochem (La Jolla, CA) was added 30 min before harvesting cells. Cells were rinsed in PBS and fixed with $1 \%$ paraformaldehyde, followed by treatment with cold ethanol, and $2 \mathrm{~N} \mathrm{HCL}$. Cell suspension $\mathrm{pH}$ was normalized with borate buffer ( $\mathrm{pH}$ 8.9). After rinsing with PBS, cells were incubated with FITC mouse anti-BRDU antibody from BectonDickinson, $30 \mathrm{~min}$ on ice, in the dark. Total DNA was counterstained with solution containing $50 \mu \mathrm{g} / \mathrm{ml}$ propidium iodine from Calbiochem and $1 \mu \mathrm{l}$ Ribonuclease A $(5 \mathrm{mg} / \mathrm{ml})$ from Worthington Biochemical. Cell cycle distribution determined by PI staining and DNA synthesis detected by BRDU uptake were analyzed by flow cytometry using a Becton-Dickinson FACScan ${ }^{\circledR}$ and CellQuest software.

\section{Results}

TIMP-1 expression and apoptosis. To determine whether soluble components of the ECM such as MMPs and their inhibitors regulate apoptosis in nonadhesion-dependent fashion, we correlated the expression of these components with the response of a series of human, Burkitt's lymphoma cell lines to cold-shock-induced apoptosis (Table I). Apoptosis was determined by morphology and flow cytometry as explained in Methods. TIMP-1 expression in these Burkitt's cell lines, determined by Northern and Western blot analysis (Fig. 1), showed $100 \%$ correlation with resistance to cold-shock-induced apoptosis. Four of the nine cell lines tested are TIMP-1 positive and did not undergo induction of apoptosis after cold shock while TIMP-1-negative cell lines readily underwent apoptosis. This response was not associated with other markers of biologic behavior that have been well studied in these and other Burkitt's lymphoma cell lines such as patient origin, chromosomal translocation $(\mathrm{t}(8 ; 14)$ vs. $\mathrm{t}(8 ; 22))$, presence of p53 mutation, or level of c-myc expression (14-17). Although all TIMP-1-positive lines were infected with EBV, both EBVpositive and negative lines were TIMP-1 negative. Some of the Burkitt's cell lines studied expressed MMP-9 as assayed by zy- 
Table I. Correlation of Burkitt's Lymphoma Cell Line

Phenotype with Susceptibility to Programmed Cell Death

\begin{tabular}{llccccc}
\hline Cell line & Origin/translocation & EBV & p53 & TIMP-1* & Gel B & Apoptosis \\
\hline PA682 & American [t(8;22)] & + & + & + & + & - \\
AG876 & African [t( $(8 ; 14)]$ & + & - & + & - & - \\
DW6 & American [t(8;14)] & + & - & + & - & - \\
Jijyoe & African [t(8;14)] & + & + & + & + & - \\
Raji & African [t(8;14)] & + & + & - & + & + \\
JD38 & American [t(8;14)] & - & + & - & + & + \\
Daudi & African [t(8;14)] & + & + & - & - & + \\
EW36 & American [t(8;14)] & - & - & - & - & + \\
ST46 & American [t(8;14)] & - & + & - & - & + \\
& & & & & & \\
\hline
\end{tabular}

Cell lines were established from patients with malignant lymphoma and small noncleaved, Burkitt's subtype, and include African and American Burkitt's as well as cases with the $t(8 ; 14)$ and $(8 ; 22)$ translocations. Origin, translocation, EBV, and p53 mutation data provided in Methods. *TIMP-1 expression determined by Northern and Western blot (Fig. 1). Gelatinase B expression was determined by zymography as previously reported. Apoptosis was induced by cold shock and detected by examination of morphology in culture for typical apoptotic changes and by flow cytometry using changes in light scatter characteristics as described in Methods.

mography (data not shown), but secretion of this MMP is not related with susceptibility to PCD (Table I).

In most lymphoid cell lines, PCD is induced by withdrawal of serum growth factors. The fetal bovine serum commonly used in tissue culture is a source of TIMP-1, and as reported by Hayakawa et al. (13), depletion of TIMP-1 from the serum is necessary to demonstrate the growth effects of TIMP-1 in several cell lines. The Burkitt's lymphoma cell line AG876 expresses high levels of TIMP-1 and is resistant to induction of PCD by incubation in serum-free media. Neutralization of secreted TIMP-1 by incubation of AG876 cells with anti-TIMP-1 antibody results in a fourfold increased induction of apoptosis under serum-free conditions $(24.03 \pm 0.6 \%$ [SD] apoptotic AG876 cells in anti-TIMP-1-treated compared with $6.9 \pm 1.05 \%$ [SD] apoptotic AG876 cells in controls, determined by TUNEL/ PI in duplicate determinations of two experiments). These results indicate that resistance to apoptosis is associated with TIMP-1 expression in Burkitt's lymphoma cell lines. No other biological parameter studied in these tumors shows correlation with apoptosis.

TIMP-1 protects against $P C D$. Recombinant TIMP-1 inhibited PCD induced by serum starvation (Fig. $2 A$ ), cold shock (Fig. $2 B$ ), and Fas activation (data not shown) in the TIMP-1 nonexpressing, EBV-negative JD38 cell line. Cell viability in serum deprivation was dose dependent in the JD38 cells incubated with 1.4-143 nM rTIMP-1 for 48 h (Fig. $2 A$ ) with 50\% survival observed at $<10 \mathrm{nM}$ TIMP-1. Saturable cell surface binding of TIMP-1 by JD38 cells was detected (data not shown) at levels similar to that observed in other cell lines (22). Specificity of TIMP-1 antiapoptotic effect is demonstrated by incubating JD38 cells with TIMP-1 $(50-250 \mathrm{ng} / \mathrm{ml})$, TIMP-2 (250-500 $\mathrm{ng} / \mathrm{ml})$, and the synthetic MMP inhibitor BB-94 $(5 \mu \mathrm{M})$ before cold-shock treatment. Fig. $2 B$ shows a reduction in percentage of apoptotic cells as determined by DNA content and TUNEL method in cells pretreated with TIMP-1, while there is no decrease in apoptosis in TIMP-2-
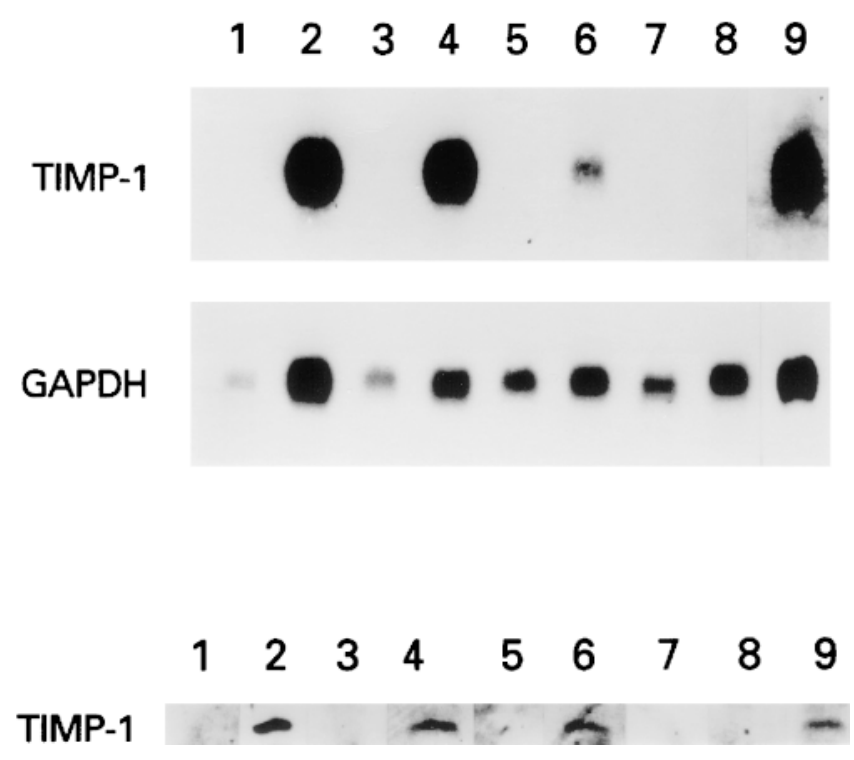

Figure 1. TIMP-1 expression in Burkitt's lymphoma cell lines. (top) Northern blot analysis of Burkitt's lymphoma cell lines probed with TIMP-1 and GAPDH. Lane 1, ST46; lane 2, AG876; lane 3, EW36; lane 4, PA682; lane 5, Daudi; lane 6, DW6; lane 7, JD38; lane 8, Raji; lane 9, Jijyoe. (bottom) Western blot analysis of TIMP-1 in conditioned media from Burkitt's lymphoma cell lines. Lane 1, ST46; lane 2, AG876; lane 3, EW36; lane 4, PA682; lane 5, Daudi; lane 6, DW6; lane 7, JD38; lane 8, Raji; lane 9, Jijyoe.

and BB-94-treated cells. Recombinant TIMP-1 inhibited PCD ( $33 \%$ decrease of apoptosis from controls) by serum starvation in germinal center $\mathrm{B}$ cells $\left(\mathrm{CD} 20^{+}\right.$and $\left.\mathrm{CD} 10^{+}\right)$from tonsils but did not affect apoptosis in T cells (1.2\% decrease of apoptosis from controls).

Effect of inactivated TIMP-1 on PCD. Chemical reduction and alkylation completely abrogates TIMP-1's ability to inhibit MMP activity (23) but not its antiapoptotic effect. A decrease in the percentage of cells with DNA fragmentation (determined by TUNEL/PI staining) was demonstrated in the presence of native as well as reduced and alkylated rTIMP-1 (29 $\pm 8.3 \%$ [SD]) and $20 \pm 6.2 \%$ [SD] apoptotic cells), respectively, as compared with cells cold-shocked in the absence of rTIMP-1 (61 $\pm 10.2 \%$ [SD] apoptotic cells). A dose of $1.4 \mathrm{nM}$ of reduced and alkylated rTIMP-1 was as effective as native rTIMP-1 in suppressing cold-shock-induced apoptosis. Similar effects are observed when specific protease activity associated with PCD induction is determined. Caspase-3 activation is a critical event in the PCD pathway. Activation of this protease is indicative of initiation of the apoptotic cascade (4). Fig. $2 C$ shows decreased percentage of cells with caspase- 3 activity in JD38 cells pretreated with both native rTIMP-1 $(13 \pm 4.0 \%$

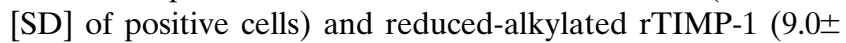
$2.5 \%$ [SD] of cells with caspase-3 activity), compared with caspase- 3 activity of cells cold-shocked in the absence of exogenous TIMP-1 (29 $\pm 5.0 \%$ [SD] of positive cells). JD38 cells have a demonstrable caspase-3 activity of 7.8 $\pm 1.6[\mathrm{SD}]$ in the absence of cold shock. This further indicates that TIMP-1 protective effect is specific and is not due to inhibition of MMP activity. Also, this result demonstrates that TIMP-1 modulation of the apoptotic pathway results in downregulation of caspase-3 


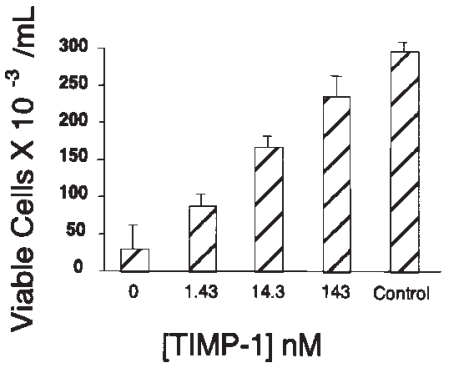

B
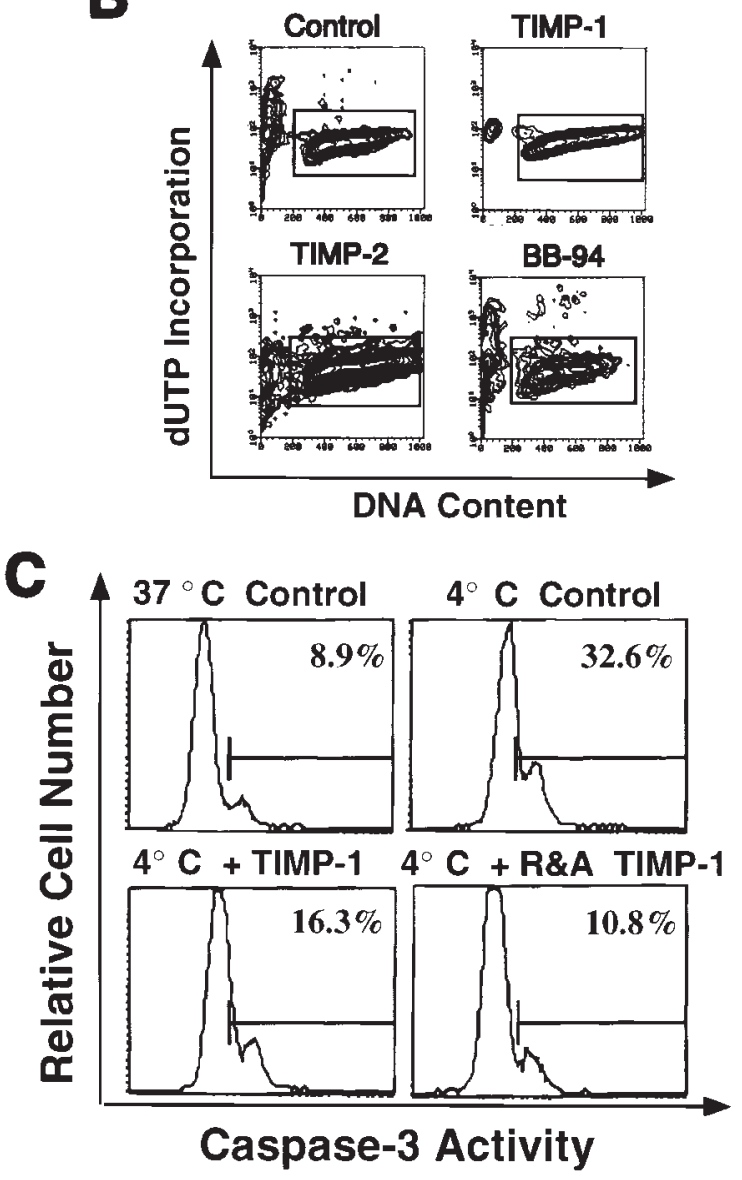

Figure 2. Exogenous rTIMP-1 suppresses PCD and caspase-3 in the Burkitt's lymphoma cell line JD38. ( $A$ ) TIMP-1 dose response in serum-deprived conditions. JD38 cells were incubated for $48 \mathrm{~h}$ in serum-free media with 1.43-143 nM rTIMP-1. Results are reported as the number of viable cells as determined by Trypan blue exclusion viability assay. Results represent mean \pm SD of duplicates of two analyses. (B) Susceptibility to cold-shock-induced apoptosis of JD38 cells as determined by TUNEL (y-axis) and a shift in total DNA as result of DNA fragmentation (x-axis). Boxed area indicates viable cells. Increased viability (85\%) is observed in cells treated with $250 \mathrm{ng} / \mathrm{ml}$ TIMP-1 as compared with untreated cells $(54 \%)$ while treatment with $500 \mathrm{ng} / \mathrm{ml}$ TIMP-2 and $5 \mu \mathrm{M}$ BB-94 shows viability of $56 \%$ and $52 \%$, respectively. $(C)$ Cold-shocked cells pretreated with $1.4 \mathrm{nM}$ reduced and alkylated (R\&A) TIMP-1 also show a decreased number of cells with caspase-3 activity (10.8\%) similar to the effect of native protein (TIMP-1) while an increased caspase activity (32\%) is observed in cells cold-shocked in the absence of TIMP-1 (untreated). Endogenous caspase- 3 activity at $37^{\circ} \mathrm{C}$ is also shown. Similar results obtained with TUNEL/PI are discussed in the text. $\mathrm{x}$-axis, log fluorescence re- activity and suggests that TIMP-1 effects are mediated upstream of activation of this cell-death protease. TIMP-1 does not inhibit caspase-3 activity (data not shown).

TIMP-1 upregulation in JD38 cells inhibits PCD. A direct TIMP-1 effect was demonstrated by inducing TIMP-1 expression in the EBV-negative JD38 cells and selection of independent cell clones as explained in Methods. Fig. $3 A$ shows expression of TIMP-1 in parent cells, three clones carrying empty LXSN vector, and four TIMP-1-JD38 cell clones as detected by Northern blot analysis. Western blot analysis of conditioned media demonstrated TIMP-1 expression and secretion by the TIMP-1-expressing clones T8, T20, and T24 but not detectable TIMP-1 in the parental line JD38 or LXSN controls (Fig. $3 \mathrm{~B}$ ). The TIMP-1 protein was functional as demonstrated by reverse zymography (data not shown). The JD38 parental cells, LXSN-JD38 cell clones, as well as TIMP-1JD38 cell clones, were examined for susceptibility to induction of PCD by various stimuli. Cells were observed periodically from 4-72 $\mathrm{h}$ after any of the following treatments: cold shock at $4^{\circ} \mathrm{C}$, anti-CD95 (anti-Fas/APO) activating antibody, serum deprivation, or $\gamma$-radiation. PCD was assessed by morphology (not shown), TUNEL method (TdT incorporation of labeled nucleotides into DNA strand breaks), PI staining (decreased DNA content due to DNA fragmentation), and light scatter changes (decreasing size and increasing granularity of cells, not shown). Table II shows a summary of percentage of apoptotic cells as determined by TUNEL/PI after treatment for each of the JD38 cell lines. Induction of TIMP-1 expression in three independent JD38 cell clones, each with a unique integration site, is associated with inhibition of apoptosis initiated by all methods studied as shown in Table II. Moreover, neutralization of secreted TIMP-1 in clones T20 and T24 with monoclonal anti-TIMP-1 antibody restored sensitivity to serum starvation while treatment with anti-TIMP-2 or isotype control did not (Fig. 4), indicating that it is secreted TIMP-1 that prevents apoptosis. These results in conjunction with our preliminary observations of cell surface binding of TIMP-1 by JD38 cells suggest that TIMP-1 effect may be receptor mediated.

To determine whether TIMP-1 protective effect was dependent on withdrawal from cell cycle, parent, LXSN-JD38, and TIMP-1-D38 cell clones 20 and 24 were cultured in the absence or presence of serum for 1-5 d, and changes in cell cycle distribution were detected by PI staining and DNA synthesis monitored by BRDU uptake. Fig. 5 shows flow cytometric analysis of these parameters for LXSN-JD38 and TIMP-1JD38 clone 24. A decreasing percentage of cells incorporating BRDU is demonstrated by control LXSN-JD38 cells, with $44.3 \%$ of cells synthesizing DNA in the presence of serum, decreasing to $9.6 \%$ by $48 \mathrm{~h}$ in the absence of serum. TIMP-1JD38 cells demonstrate a higher percentage of cells actively incorporating nucleotides throughout the same treatment times. These results suggest both that the TIMP-1-protective effect does not involve cell cycle perturbations and that control cells die while progressing through the cycle.

Effects of TIMP-1 on apoptotic proteins. Bcl-2 has been shown to inhibit apoptosis in B cells as well as in numerous other cell

sulting from the cleavage of flourogenic peptide specific for caspase-3; $y$-axis, percentage of cells. Representative data of triplicate determinations of three experiments. 
Table II. Summary of Induction of Programmed Cell Death in JD38 Cells with Retroviral Transduced TIMP-1 Expression as Determined by TUNEL/PI

\begin{tabular}{|c|c|c|c|c|c|}
\hline \multirow[b]{2}{*}{ Cell line } & \multicolumn{5}{|c|}{ Method for induction of programmed cell death (\% apoptotic cells) } \\
\hline & Untreated & Cold shock & anti-FAS & $\gamma$-Radiation & Serum free \\
\hline JD38 & $8.4 \pm 4.3$ & $56.3 \pm 7.5$ & $29.0 \pm 8.0$ & $32.0 \pm 1.4$ & $87.0 \pm 3.0$ \\
\hline LXSN (Control) & $5.8 \pm 2.7$ & $43.6 \pm 9.0$ & $40.0 \pm 13.0$ & $34.1 \pm 5.7$ & $78.0 \pm 13.0$ \\
\hline TIMP-1 (Clone 8) & $2.4 \pm 0.6$ & $1.3 \pm 0.9$ & & & \\
\hline TIMP-1 (Clone 20) & $5.5 \pm 3.5$ & $8.1 \pm 0.6$ & $5.4 \pm 3.4$ & $3.2 \pm 1.2$ & $6.1 \pm 2.5$ \\
\hline TIMP-1 (Clone 24) & $3.4 \pm 1.1$ & $13.2 \pm 9.0$ & $2.1 \pm 0.1$ & $4.7 \pm 1.2$ & $5.7 \pm 0.8$ \\
\hline
\end{tabular}

Apoptosis was detected by TUNEL in conjunction with PI staining for the detection of sub Go/G1 DNA peak as explained in Methods. These results were confirmed by at least three methods: light-microscopy morphology, forward and side scatter, and caspase-3 activity (not shown). Results are expressed as percentage of apoptotic cells, mean $\pm \mathrm{SD}$ of duplicate determinations of three flow-cytometric analyses.

types $(1,2,24-26)$. To determine whether Bcl-2 or related proteins are implicated in the TIMP-1 protective effect, TIMP-1JD38 cell clones and control LXSN and parent JD38 cells were assayed for their expression of these antiapoptotic proteins by Western analysis. Although both control and TIMP-1-JD38 express Bcl-2, upregulation of TIMP-1 does not further enhance expression of this protein. However, induction of TIMP-1 clearly upregulates Bcl- $\mathrm{X}_{\mathrm{L}}$ in TIMP-1-JD38 cell clones as compared with LXSN-JD38 cells (Fig. 6). Also, cells were all negative for the Bcl-2 homologue Mcl-1 (27) (data not shown). In addition to controlling several genes in B lymphocytes, including immunoglobulin light chain gene, the transcription factor $\mathrm{NF}-\kappa \mathrm{B}$ has been reported to regulate expression of genes involved in apoptosis (28-30). After immunodetection of Bcl- $\mathrm{X}_{\mathrm{L}}$,

A

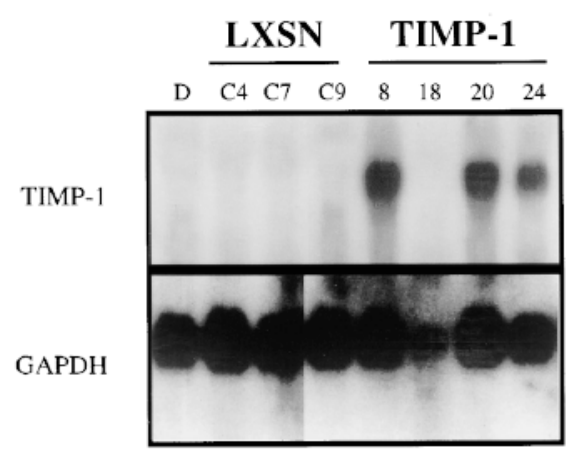

B

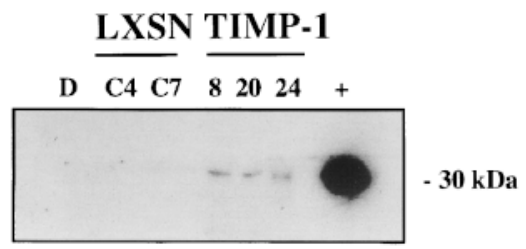

Figure 3. TIMP-1 expression in LXSN-transduced JD38 cells. (A) Northern blot analysis of parent line JD38 (lane $D$ ), LXSN vector control clones (lanes $C 4, C 7$, and $C 9$ ), and LXSN-TIMP-1 clones (lanes 8,18,20, and 24). Northern blots were probed for TIMP-1 and reprobed with GAPDH probe for loading control. $(B)$ Western blot analysis of secreted TIMP-1 in parent JD38 cells (lane $D$ ), LXSN vector control clones (lanes $C 4$ and $C 7$ ), and LXSN-TIMP-1 clones (lanes 8,20 , and 24); rTIMP-1 (50 ng) was used as positive control $($ lane + ). Lane numbers correspond to clone numbers.

the same blot in Fig. 6 was reprobed with an antibody against NF-кB p65 (Rel A). No change in the cytoplasmic expression of NF-кB was observed for any of JD38 cell lines (Fig. 6). However, higher expression of the NF- $\mathrm{B}$ inhibitor $\mathrm{I} \kappa \mathrm{B} \alpha$ is observed in TIMP-1-expressing cell clones $(20,24)$, indicating a decreased in NF-кB activity (Fig. 6). Furthermore, TIMP-1 suppression of PCD did not correlate with levels of cell surface CD95 expression (data not shown). These results suggest that TIMP-1 antiapoptotic mechanism is not mediated by Bcl- 2 or suppression of CD95 expression, but likely by inducing Bcl- $\mathrm{X}_{\mathrm{L}}$.

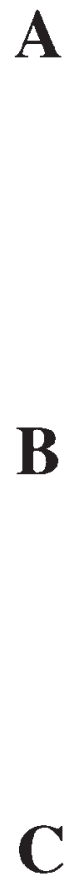

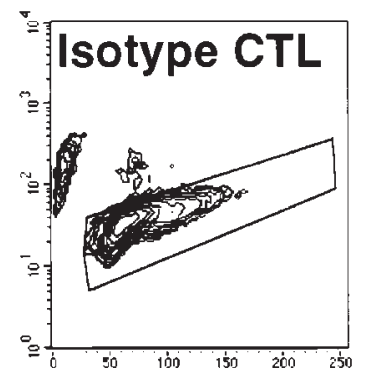
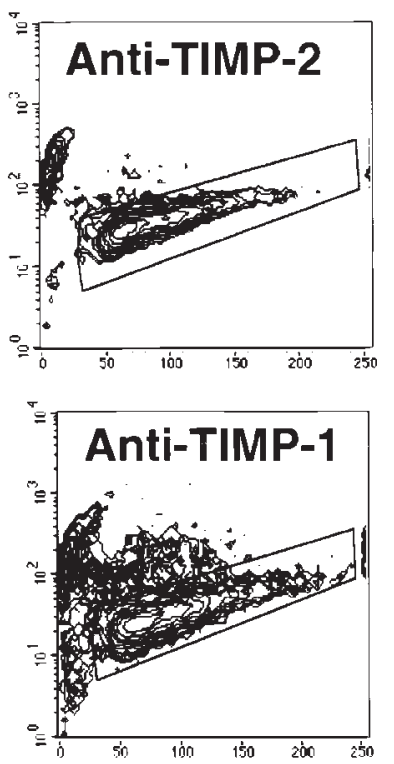

Figure 4. Neutralization of TIMP-1 reverses PCD suppression. TIMP-1JD38 cell clones were incubated for $48 \mathrm{~h}$ in serum-free media with 5 $\mu \mathrm{g} / \mathrm{ml}$ of the following murine monoclonal antibodies: isotype control $(A)$, anti-TIMP-2 $(B)$, and anti-TIMP-1 (C). Boxed region indicates viable cells. Treatment with anti-TIMP-1 decreased percentage of viable cells (66.2\%) due to apoptosis as compared with isotype control $(85.0 \%)$ and anti-TIMP-2 (87.05\%). Apoptosis was determined by TUNEL (yaxis) and shift in DNA content by propidium iodide (x-axis) as explained in Methods. 


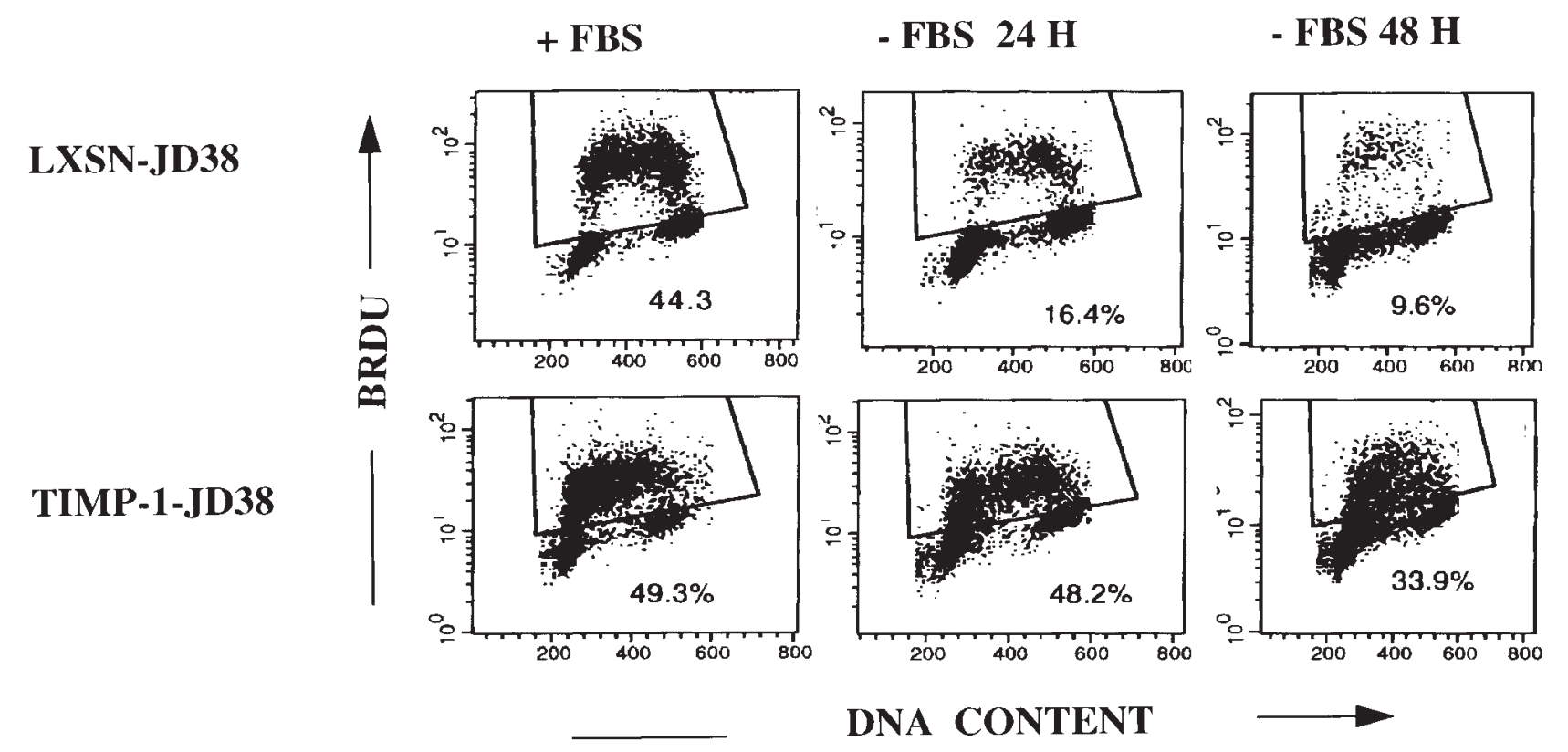

Figure 5. Effect on DNA synthesis of upregulated TIMP-1 in JD38 cells. Parent JD38 cells, LXSN-JD38, and TIMP-JD38 cell clones were incubated in the presence $(+F B S)$ or absence $(-F B S)$ of serum for 1-5 d; DNA synthesis was monitored by BRDU (y-axis) uptake as explained in Methods, and cell cycle distribution by staining total DNA with propidium iodine (x-axis), flow cytometric analysis of dot plots is shown. In contrast to serum condition, serum-deprived LXSN-JD38 cells show a continuing reduction in the fraction of cells actively synthesizing DNA (boxed), while TIMP-1-JD38 clone 24 cells under the same conditions maintain similar percentage of BRDU uptake as those of TIMP-JD38 cells in serum. Only results from 24 and $48 \mathrm{~h}$ are shown. By day 5, BRDU uptake in parent JD38, LXSN, and TIMP-1 JD38 was 3.84\%, 4.97\%, and $18.75 \%$, respectively (not shown).

Also, upregulation of Bcl- $\mathrm{X}_{\mathrm{L}}$ by TIMP-1 appears to be independent from NF-кB activation in TIMP-1-expressing JD38 cells.

\section{Discussion}

The extracellular matrix has been implicated in the regulation of apoptosis of epithelial cells in an attachment-dependent fashion. In these studies, ECM was demonstrated to modulate PCD and effectors such as capases through integrin receptors (4). More recently, extracellular matrix factors were shown to control PCD of hemato-lymphoid cells $(5,6,31)$. Using a human melanoma cell line, Valente et al. have shown that TIMP-2 inhibits tumor cell invasion and that TIMP-2 overexpressing tumor clones were found to be more resistant to apoptosis than parental and control melanoma cells (32). A recent report in this journal demonstrates that TIMP-3 promotes apoptosis in rat vascular smooth muscle cells (33). These studies support the idea that TIMPs can exert different activities in addition to inhibition of MMP, including modulation of PCD. However, in both of these studies, the mechanism for the effect of TIMP-2 and TIMP-3 on PCD is not addressed. Our laboratory and others have previously reported on the expression of MMPs and their endogenous inhibitors (TIMPs) by normal and neoplastic lymphocytes $(7,34)$. We have found high-level expression of TIMP-1 in normal activated tonsillar B cells as well as in highgrade B cell lymphoma cell lines, frequently in the absence of MMP expression (7). In the present study, we have found TIMP-1 expression is associated with resistance to apoptosis in Burkitt's lymphoma cell lines and that TIMP-1 can inhibit apoptosis in normal tonsillar B cells.
The suppression of PCD is a novel action for TIMP-1. Our data further demonstrates that this effect is TIMP-1 specific and is not secondary to MMP inhibition. The ability of TIMP-1 to inhibit apoptosis in an MMP-independent manner is consistent with observations of growth promotion by TIMPs in a variety of cell types (13). Hayakawa et al. have shown that TIMP-1 promotes cell survival in serum-free conditions for a wide variety of cell lines sensitive to serum deprivation including lymphoid, myeloid, endothelial, fibroblasts, hepatoma, breast carcinoma, and chondrocyte cell lines (13). Although these authors did not measure apoptosis in these cell lines, it is known that they do undergo apoptosis under conditions of serum starvation. Addition of TIMP-1 was sufficient to maintain cell growth and viability, suggesting that TIMP-1 may have inhibited serum-starvation induced PCD in these lines representing multiple lineages. TIMP-1 inhibits apoptosis in mouse mammary epithelial cells $(3,4)$. This effect was attributed to inhibition of MMP activity and preservation of cell-matrix contacts. The possible direct antiapoptotic effect of TIMP-1 was not examined in this system. Preservation of cell-matrix is clearly not the mechanism of TIMP-1 suppression of PCD in Burkitt's lymphoma cell lines. First, reduced-alkylated TIMP-1, completely devoid of MMP inhibitory activity, results in PCD suppression. In addition, TIMP-2 or the synthetic inhibitor BB-94 failed to protect from PCD, even though the levels of BB-94 used should completely inhibit a wide spectrum of metalloproteinases, including MMPs. The ability of TIMP-1 to exert antiapoptotic effects independently of its MMP inhibitory effect is consistent with other studies that demonstrated TIMP-1 cell growth modulatory effects unrelated to its ability to act as MMP inhibitor (12). 

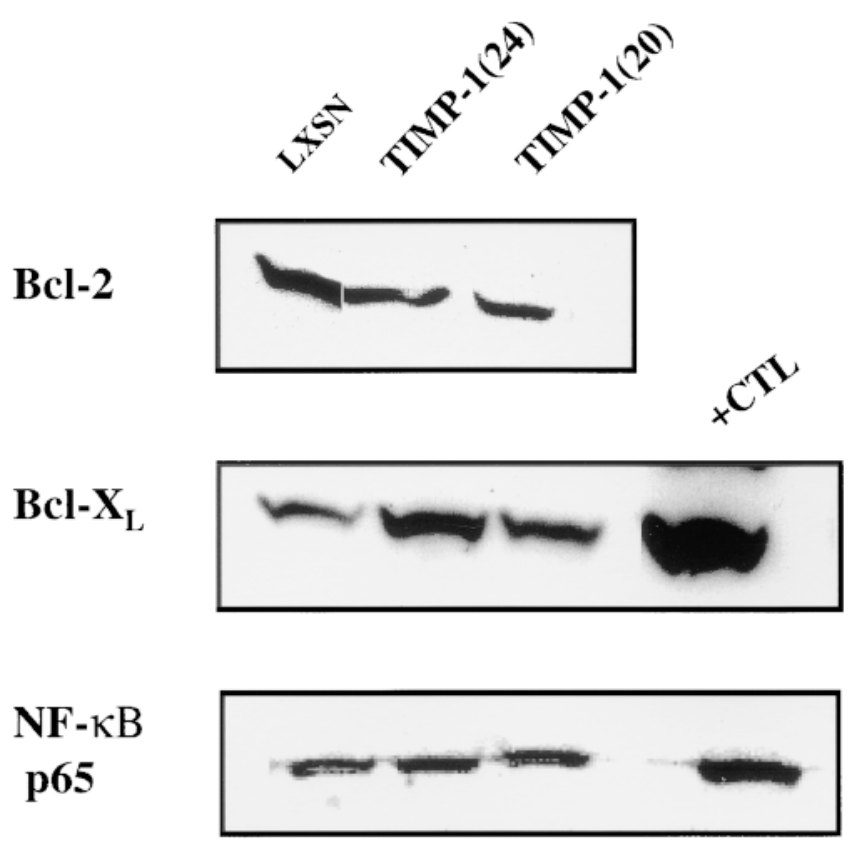

$\mathbf{I} \kappa \mathbf{B} \alpha$

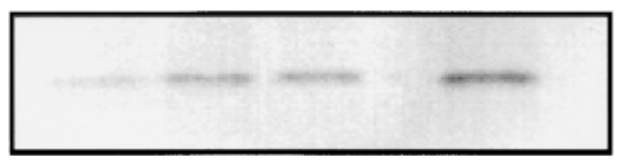

Figure 6. Expression of Bcl-2-related proteins in JD38 cell lines. Expression of Bcl-2, Bcl- $\mathrm{X}_{\mathrm{L} / \mathrm{S}}$ in parent JD38 cells, LXSN-JD38, and TIMP-1-JD38 clones 20, 24 were detected by Western blot analysis as explained in Methods. Parental and LXSN-JD38 cells express equal levels of Bcl-2, demonstrating that upregulation of TIMP-1 in JD38 cells does not significantly enhance $\mathrm{Bcl}-2$ expression. Upregulation of TIMP-1 in JD38 cells induces higher expression of Bcl- $\mathrm{X}_{\mathrm{L}}$ in TIMP1-JD38 cell clones 20 and 24 as compared with LXSN-JD38 controls. A high TIMP-1 expressing Burkitt's line AG876 is included as positive control $(+C T L)$. The same $\mathrm{Bcl}-\mathrm{X}$ blot was stripped and reprobed with antibody against p-65 NF- $\mathrm{B}$. No significant changes in the expression of this transcription factor is observed in JD38 cell lines, indicating that upregulation of TIMP-1 does not affect cytoplasmic concentration of NF- $\mathrm{BB}$. However, TIMP-1 upregulation induces the

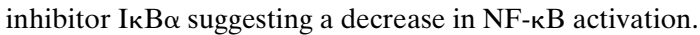

TIMP-1 inhibition of apoptosis provides a possible biological basis for the apparently paradoxical negative prognosis that is associated with increased TIMP-1 expression in many solid tumors $(9,36-40)$. If TIMP-1's sole biological activity is inhibition of MMPs, elevated TIMP-1 levels would be expected to decrease invasion and metastasis, thereby improving prognosis. However, TIMP-1 levels are elevated in human colorectal cancer compared with normal colonic tissue (37), and higher TIMP-1 levels are associated with lymph node and distant mestastasis in this disease (38). Increased TIMP-1 is an important negative prognostic indicator in gastric carcinoma (9). In patients with non-small cell lung carcinoma, a significant decrease in survival was observed with high TIMP-1 expression (39). Enhanced levels of TIMP-1 expression in breast cancer are associated with distant metastasis and poor outcome (36, 40). In addition, serum TIMP-1 levels are significantly increased in patients with pancreatic carcinoma, and when detected in combination with CA19-9 or carcinoembryonic anti- gen, are a highly specific marker for disease (41). These findings have led many of these authors to propose independently that TIMP-1 is a growth and/or survival factor $(9,36,38$, 39). While we realize that these observations are not evidence of a direct antiapoptotic effect, they are highly suggestive that TIMP-1 may exert growth promoting activity in multiple systems.

TIMP-2's failure to inhibit PCD in Burkitt's lymphoma cell lines is in contrast to its observed antiapoptotic activity in melanoma cell lines (32) and suggests that the effects of various TIMPs on apoptosis may be tissue specific. This is further supported by our observation that TIMP-1 inhibited apoptosis in normal tonsillar B cells but not T cells. In addition, TIMP-1's inhibition of apoptosis may be dependent upon stage of differentiation and or cellular millieu. We have previously reported that TIMP-1 is expressed in isolated tonsillar B cells but not in peripheral blood $\mathrm{B}$ cells. Moreover, maintaining isolated tonsillar B cells in culture resulted in decreased TIMP-1 expression over time compared with freshly isolated tonsillar B cells, with a significant decrease in TIMP-1 expression noted by $4 \mathrm{~h}$ (7). In the current study, TIMP-1 inhibited PCD in tonsillar germinal center B cells and Burkitt's lymphomas, which are also germinal center in origin. Thus TIMP-1 protection from PCD may be dependent upon B cell differentiation. Germinal center tonsillar B cells cultured for $16 \mathrm{~h}$ in serum-free media undergo apoptosis, an event that is not unexpected in view of their significantly decreased TIMP-1 expression (7). The ability of rTIMP-1 to protect these B cells from apoptosis indicates that germinal center $\mathrm{B}$ cells are sensitive to this biological activity of TIMP-1, while the proper cellular milieu (i.e., germinal center extracellular matrix and support cells) appears necessary to maintain TIMP-1 expression.

The growth promoting effects of TIMP-1 do not appear to be due to withdrawal from cell cycle, as has been observed for the survival activity of the ECM (42). In this study, TIMP-1JD38 cells cultured in serum-deprived conditions continued cell cycle for extended periods of time. These results support TIMP-1 as an antiapoptotic factor that inhibits PCD while allowing cell growth in stress. The observation that TIMP-1 is secreted by these cell lines and binds to the cell surface in combination with the demonstration that neutralization of secreted TIMP-1 reverses suppression of apoptosis, suggests that TIMP-1 acts through a receptor-mediated autocrine loop. Other investigators $(12,13,22)$ have postulated the presence of such a receptor. Studies in our laboratory are underway to isolate and characterize this receptor.

The central role of apoptosis in the homeostasis of lymphoid tissues is now widely acknowledged. In lymphocytes there are at least two independent pathways for initiation of PCD: the tumor necrosis (TNF)/nerve growth factor (NGF) receptor family pathway (involved in numerous functions limiting immunoresponses and $\mathrm{T}$ cell cytotoxity), and the Bcl-2 family-dependent pathway, initiated by factors such as irradiation, cytotoxic drugs, and serum deprivation (43-46). Except for Bcl- $\mathrm{X}_{\mathrm{L}}, \mathrm{Bcl}-2$ family members have not been shown to directly alter CD95/Fas pathway in lymphocytes $(45,46)$. Results of the present study demonstrate that TIMP-1 protects B cells from apoptosis induced by both $\mathrm{Bcl}-2-$ dependent pathways (serum starvation and $\gamma$-radiation) and $\mathrm{Bcl}-2$ independent ones such as Fas (43-45). Most Burkitt's lymphoma lines are prone to apoptosis and have been reported to be highly sensitive to cold shock (19). Although factors implicated in the 
control of this pathway are yet to be described, some reports suggest that Bcl-2 is not one of them $(19,47)$, and this may be a third pathway for induction of PCD that TIMP-1 can also protect against. In the present study, TIMP-1 did not affect Bcl-2 or CD95 expression. However Bcl- $\mathrm{X}_{\mathrm{L}}$ is upregulated in the TIMP-1-JD38 cell clones, indicating that the TIMP-1 protective effect might be in part mediated through induction of $\mathrm{Bcl}-\mathrm{X}_{\mathrm{L}}$. Bcl- $\mathrm{X}_{\mathrm{L}}$ is known to not only overlap with Bcl-2 in protection from apoptosis but also exerts its protective effect in pathways not controlled by Bcl-2, such as the Fas/TNF pathway $(45,46,48)$. Also, in contrast to B cell studies showing induction of antiapoptotic proteins by NF-кB $(28,29)$, the present study demonstrates upregulation of the inhibitor Iк $\mathrm{B} \alpha$ (48) in TIMP-1-JD38 clones. Therefore, NF-кB activation may not be involved in the induction of antiapoptotic proteins by TIMP-1. Interestingly, this decreased NF- $\mathrm{B}$ activity is also supported by our previous results showing downregulation of immunoglobulin expression in TIMP-1-positive cells, since immunoglobulin expression is known to be controlled by NF- $\mathrm{B}$ (49). Future studies are needed to conclusively determine the role of NF-кB or to identify other transcription factors involved in TIMP-1's antiapoptotic effect.

Overall, this study supports a novel role for TIMP-1 in the control of apoptosis in B cells. Results discussed here provide a biological basis for the observed negative prognosis associated with increased TIMP-1 expression in non-Hodgkin's lymphomas, as well as many solid tumors $(8-10,36)$. Further studies are indicated to determine if TIMP-1 inhibition of apoptosis in the tumor cells alters the prognosis in these patients.

\section{Acknowledgments}

The authors thank Dr. Megan Lim for performing the reverse zymograph analysis, Dr. Peter Brown, British Biotechnology, Ltd., for supplying BB-94, Dr. Anita Yu for reduced and alkylated TIMP-1, and Dr. Kevin Gardner for his valuable advice and NF-кB antibodies.

\section{References}

1. McDonnell, T.J., and S.J. Korsmeyer. 1991. Progression from lymphoid hyperplasia to high grade malignant lymphoma in mice transgenic for the $\mathrm{t}(14$; 18). Nature. 349:254-256.

2. Cohen, J.J. 1991. Programmed cell death in the immune system. Adv. Immunol. 50:55-63.

3. Alexander, C.M., E.W. Howard, M.J. Bissell, and Z. Werb. 1996. Rescue of mammary epithelial cell apoptosis and entactin degradation by tissue inhibitor of metalloproteinase-transgene. J. Cell Biol. 135:1669-1677.

4. Boudreau, N., C.J. Sympson, Z. Werb, and M. Bissell. 1995. Suppression of ICE and apoptosis in mammary epithelial cells by extracellular matrix. Science. 267:891-893.

5. McGeehan, G.M., J.D. Becherer, R.C. Bast, B. Champion, K.M. Connolly, J.G. Conway, F. Furdon, S. Karp, S. Kidao, A.B. McElroy, et al. 1994. Regulation of tumor necrosis-factor alpha processing by metalloproteinase inhibitor. Nature. 370:558-561.

6. Tanaka, M., T. Suda, K. Haze, N. Nakamura, N. Sato, F. Kimura, K. Motoyoshi, M. Mizuki, S. Tagawa, S. Ohga, et al. 1996. Fas ligand in human serum. Nat. Med. 2:317-322.

7. Stetler-Stevenson, M., A. Mansoor, M.S. Lim, P. Fukushima, J. Kehrl, G. Marti, K. Ptaszynski, J. Wang, and W.G. Stetler-Stevenson. 1997. Expression of matrix metalloproteinases and tissue inhibitors of metalloproteinases (TIMPs) in reactive and neoplastic lymph nodes. Blood. 89:1708-1715.

8. Kossakowska, E.E., S.J. Urbanski, and D.E. Edwards. 1991. Tissue inhibitor of metalloproteinases-1 (TIMP-1) RNA is expressed at elevated levels in malignant non-Hodgkin's lymphomas. Blood. 77:2474-2481.

9. Mimori, K., M. Mori, T. Shiraishi, T. Fujie, K. Baba, M. Haraguchi, R. Abe, H. Ueo, and T. Akiyoshi. 1997. Clinical significance of tissue inhibitor of metalloproteinase expression in gastric carcinoma. Br. J. Cancer. 76:531-536.

10. Mansoor, A., B. Birkedal-Hansen, M.S. Lim, L. Guedez, W.G. StetlerStevenson, and M. Stetler-Stevenson. 1997. TIMP-1 expression correlates with histologic grade in B-cell lymphomas. Mod. Pathol. 10:130a. (Abstr.)

11. Stetler-Stevenson, W.G., N. Bersh, and D.W. Golde. 1992. Tissue inhibitor of metalloproteinase-2 (TIMP-2) has erythroid potentiating activity. FEBS. 296:231-234.

12. Chesler, L., D.W. Golde, N. Bersch, and M. D. Johnson. 1995. Metalloproteinase inhibition and erythroid potentiating are independent activities of tissue inhibitor of metalloproteinase-1. Blood. 86:4506-4515.

13. Hayakawa, T., K. Yamashita, K. Tanzawa, E. Uchijima, and K. Iwata. 1992. Growth-promoting activity of tissue inhibitor of metalloproteinases(TIMP-1) for a wide range of cells, a possible new growth factor in serum. FEBS Lett. 298:29-32.

14. Anwar, N., D.W. Kingma, A.R. Bloch, R. Mourad, M. Raffeld, J. Franklin, I. Magrath, N. Bolkainey, and E.S. Jaffee. 1995. The investigation of Epstein-Barr-virus sequences in 41 cases of Burkitt's lymphomas from Egypt: epimediologic correlation. Cancer. 76:1241-1252.

15. O'Connor, P.M., J. Jakman, D. Jondle, K. Bhatia, I. Magrath, and K.W. Khon. 1993. Role of the p53 tumor suppresser gene in cell cycle arrest and radiosensitivity of Burkitt's lymphoma cell lines. Cancer Res. 53:4776-4780.

16. Gaidano, G., P. Ballerini, J.Z. Gong, G. Inghiriami, A. Neri, E.W. Newcomb, I. Magrath, D.M. Knowels, and R. Dalla-Favera. 1991. P53 mutations in human lymphoid malignancies: association with Burkitt's lymphoma and chronic lymphocytic leukemia. Proc. Natl. Acad. Sci. USA. 88:5413-5417.

17. Bhatia, K., S. Fan, G. Spancler, M. Weintraub, P.M. O'Connor, J.G. Judde, and I. Magrath. 1995. A mutant p21 cyclin-dependent kinase inhibitor isolated from Burkitt's lymphoma. Cancer Res. 55:1431-1435.

18. Oliver, G.W., J.D. Leferson, W.G. Stetler-Stevenson, and D.E. Kleiner. 1996. Quantitative reverse zymography: analysis using gelatinase A and B reverse zymograms. Anal. Biochem. 244:161-163.

19. Gregory, C.D., and A.E. Milner. 1994. Regulation of cell survival in Burkitt's lymphoma: implications from studies of apoptosis following coldshock treatment. Int. J. Cancer. 57:419-426.

20. Dive, C., C.D. Gregory, D.J. Phipps, D.L. Evans, A.E. Milner, and A.H. Wyllie. 1992. Analysis and discrimination of necrosis and apoptosis (programmed cell death) by multiparameter flow cytometry. Biochem. Biophys. Acta. 1133:275-285.

21. Markwitz, D., S. Goff, and A. Bank. 1988. Construction and use of a safe and efficient amphotropic packaging cell line. Virology. 167:400-406.

22. Bertaux, B., W. Hornebeck, A.Z. Eisen, and L. Dubertret. 1991. Growth stimulation of human keratinocytes by tissue inhibitor of metalloproteinases. J. Invest. Dermatol. 97:679-685.

23. Hayakawa, T., K. Yamashita, E. Ohuchi, and A. Shinagawa. 1994. Cell growth activity of tissue inhibitor of metalloproteinases-2 (TIMP-2). J. Cell Sci. 107:2373-2379.

24. Rothstein, T.L. 1996. Signals and susceptibility to programmed cell death in B cells. Curr. Opin. Immunol. 8:362-371.

25. Guedez, L., and J. Zucali. 1996. Bleomycin-induced differentiation of bcl-2-transfected U-937 leukemia cells. Cell Growth Differ. 7:1625-1631.

26. Korsmeyer, S.J. 1992. Bcl-2: an antidote to programmed cell death. Cancer Surv. 15:105-118.

27. Bodrug, S.E., C. Aime-Sempe, T. Sato, S. Krajewski, M. Hanada, and J.C. Reed. 1995. Biochemical and functional comparisons of Mcl-1 and Bcl-2 proteins: evidence of a novel mechanism of regulating Bcl-2 family function. Cell Death Differ. 2:173-182.

28. Baker, S.J., and E.P. Reddy. 1996. Transducers of life or death: TNF receptor superfamily and associated proteins. Oncogene. 12:1-9.

29. Baeuerle, P.A., and T. Henkel. 1994. Function and activation of NF-кB in the immune system. Annu. Rev. Immunol. 12:141-179.

30. Hsing, Y., B.S. Hostager, and G.A. Bishop. 1997. Characterization of CD40 signaling determinants regulating nuclear factor- $\mathrm{\kappa}$ B activation in B cells lymphocytes. J. Immunol. 159:4898-4906.

31. Guedez, L., M.S. Lim, and W.G. Stetler-Stevenson. 1996. The role of metalloproteinases and their inhibitors in hematological disorders. Crit. Rev. Oncol. 7:205-225.

32. Valente, P., G. Fassina, A. Melchori, L. Masiello, M. Cilli, A. Vacca, M. Onisto, L. Santi, W.G. Stetler-Stevenson, and A. Albini. 1998. TIMP-2 overexpression reduces invasion and angiogenesis and protects B16F10 melanoma cells from apoptosis. Int. J. Cancer. 75:246-253.

33. Baker, A.H., A.B. Zaltsman, S.I. George, and A.C. Newby. 1998. Divergent effects of tissue inhibitors of metalloproteinase-1, -2 , or -3 overexpression on rat vascular smooth muscle cell invasion, proliferation, and death in vitroTIMP-3 promotes apoptosis. J. Clin. Invest. 101:1478-1487.

34. DiGirolamo, N., N. Tedla, A. Lloyd, and D. Wakefield. 1998. Expression of matrix metalloproteinases by human plasma cells and B lymphocytes. Eur. J. Immunol. 28:1773-1784.

35. Guedez, L., L. Courtemanch, and M. Stetler-Stevenson. 1998. Tissue inhibitor of metalloproteinase (TIMP)-1 induces differentiation and an anti-apoptotic phenotype in germinal center B-cells. Blood. In press.

36. Ree, A.H., V.A. Florenes, J.P. Berg, G.M. Maelandsmo, J.M. Nestland, and O. Fostad. 1997. High levels of messenger-RNAs for tissue inhibitors of metalloproteinases (TIMP-1 and TIMP-2) in primary breast carcinomas are associated with development of distant metastasis. Clin. Cancer. Res. 3:16231628. 
37. Stetler-Stevenson, W.G., P.D. Brown, M. Onisto, A.T. Levy, and L.A. Liotta. 1990. Tissue inhibitor of metalloproteinase-2 (TIMP-2) mRNA expression in tumor cell lines and human tumor tissues. J. Biol. Chem. 265:1393313938

38. Zeng, Z., A.M. Cohen, Z. Zhang, W.G. Stetler-Stevenson, and J.G. Guillem. 1995. Elevated tissue inhibitor of metalloproteinase-1 RNA in colorectal cancer stroma correlates with lymph node and distant metastases. Clin. Cancer Res. 1:899-906.

39. Fong, K.M., Y. Kida, P.V. Zimmerman, and P.J. Smith. 1996. TIMP-1 and adverse prognosis in non-small cell lung cancer. Clin. Cancer Res. 2:13691372.

40. McCarthy, K., G. Maguire, G. McGreal, E. McDermott, N. O'Higgins, and M.J. Duffy. 1998. High levels of TIMP-1 predict poor outcome in patients with breast cancer. Br. J. Cancer. 78:41-41.

41. Zhou, W., L.J. Sokoll, D.J. Bruzek, V.E. Velculescu, S.B. Goldin, R.H Hruban, S.E. Kern, S.R. Hamilton, D.W. Chan, B. Volgelstein, et al. 1998. Identifying markers for pancreatic cancer by gene expression analysis. Cancer Epidemiol. Biomarkers Prev. 7:109-112.

42. Wu, R.C., and A.H. Schonthal. 1997. Activation of p53-p21waf1 pathway in response to disruption of cell-matrix interactions. J. Biol. Chem. 272: 29091-29098.
43. Strasser, A., A.W. Harris, D.C. Huang, P.H. Krammer, and S. Cory. 1995. Bcl-2 and Fas/APO-1 regulate distinct pathways to lymphocyte apoptosis EMBO J. 14:6136- 6147.

44. Strasser, A. 1995. Life and death during lymphocyte development and function: evidence for two distinct killing mechanisms. Curr. Opin. Immunol. 7 : $228-234$.

45. Chiu, V.K., C.M. Walsh, C.C. Liu, J.C. Reed, and W.R. Clark. 1995. Bcl-2 blocks degranulation but not fas-based cell mediated cytotoxicity. J. Immunol. 154:2023-2032.

46. Memon, S.A., M.B. Moreno, D. Patrak, and C.M. Zacarchuck. 1995. Bcl-2 blocks glucocorticoid-but not Fas-or activation-induced apoptosis in a T cell hybridoma. J. Immunol. 155:4644-4652.

47. Milner, A.E., G.D. Johnson, and C.D. Gregory. 1992. Prevention of programmed cell death in Burkitt's lymphoma cell lines by bcl-2-dependent and independent mechanisms. Int. J. Cancer. 52:636-644.

48. Schneider, T.J., D. Grillot, L.C. Foote, G.E. Nunez, and T.L. Rothstein. 1997. Bcl-x protects primary B cells against Fas-mediated apoptosis. J. Immunol. 159:4834-4839.

49. Henkel, T., T. Machleidt, I. Alkaly, M. Kronke, Y. Benn-Neriah, and P.A. Baeuerle. 1993. Rapid proteolysis of IкB $\alpha$ is necessary for activation of transcription factor NF-кB. Nature. 365:182-185. 